\title{
Study on the Relationship between CSR Management Level and Enterprise Development Ability
}

\author{
Tiantian An ${ }^{\mathrm{a}}$, Chunfa Li \\ School of Management, Tianjin University of Technology, Tianjin 300384, China. \\ a13821677875@163.com
}

\begin{abstract}
Regression analysis was carried out for CSR management level and enterprise development ability in the same period based on 65 central enterprises in 2014. With software SPSS to carry out principal component analysis and regression analysis for the indicators and data, the result found that CSR management level is negatively related with the enterprise development ability.
\end{abstract}

Keywords: Central enterprises; CSR management level; enterprise development ability; the empirical analysis.

\section{Introduction}

Under the national advocacy in the period of "twelfth five-year", enterprises paid more and more attention to CSR and intensified the management of CSR. This behavior is largely benefit the customers, government, society and environment and so on. Then it is how to affect the enterprise that to improve CSR management level. Due to the essence of enterprise is for-profit organizations, so operators need to ensure that the enterprises can survive and develop. Enterprise development ability is a potential ability to expand and grow strength and is the source of enterprise sustainable development and value of the future. In the current so intense, complex and changeful market environment, only having a certain development ability, the enterprises can obtain sustainable competitive advantage [1]. In the new era, CSR has integrated into the enterprise management and business process and has become a development pattern of enterprise, a way of competition and management strategy. It is more and more prominent that CSR impact on the enterprise development ability. Therefore, the research on the relationship between CSR management level and enterprise development ability is very necessary for enterprise sustainable development. Due to the limited data acquisition, this paper selects 65 central enterprises as samples for empirical research and analyses the relationship between CSR management level and enterprise development ability at the same time.

\section{The Data Sources, Samples and Indexes Selection}

In this paper, the data is from corporate social responsibility reports of central enterprises released in 2014. It totally has 112 central enterprises, but due to some enterprises did not publish corporate social responsibility reports or information disclosure not entire. So this paper finally chooses 65 central enterprises as the research object.

Evaluation indexes of corporate social responsibility management level are divided into two levels in this paper. First grade index mainly has 10 indicators which include the concept of corporate social responsibility, corporate social responsibility organizational system, institutional system, into the function of management, into the business process, overseas operation, capacity building, information disclosure, stakeholder management, performance management. There are 41 secondary indicators. 
Academics have studied how to measure the enterprise development ability. Based on the existing research results, from a financial perspective, this paper considers the availability and feasibility of the data. Finally, this paper uses the main business revenue growth to reflect the enterprise development ability [2] [3].

\section{Corporate Social Responsibility Management Level Evaluation}

In order to comprehensively and systematically analyze corporate social responsibility management level, this paper considers many indicators. But each indicator can only reflect certain aspect of corporate social responsibility management and indexes may also have certain correlation with each other. Thus the information reflected the statistical data what the paper got overlaps to a certain extent. In view of this, the paper carries out integration for the above first grade indicators by using principal component analysis and extracts factors that can reflect corporate social responsibility management level. Using this way calculates the factors comprehensive score values to measure corporate social responsibility management level

This paper uses SPSS statistical software to carry out principal component analysis for the indicators of measuring corporate social responsibility management level. The analysis result of cumulative variance that each factor explain the original variable is showed in table 1. According to the default extraction principle of SPSS, the factors that the eigenvalues are greater than 1 should be extracted. Based on the table 1, we know that the paper should extract the former three factors. The three factors cover $72.72 \%$ information of 10 original indexes and give a full summary for the majority of indexes. So they are enough to reflect the essence of the sample. The factor score coefficient matrix is given when factors are analyzed, such as table 2.

Table 1 The total variance of each factor explanation

\begin{tabular}{|c|c|c|c|c|c|c|}
\hline \multirow{2}{*}{ Component } & \multicolumn{3}{|c|}{ Initial Eigenvalue } & \multicolumn{3}{c|}{ Extraction Sums of Squared Loading } \\
\cline { 2 - 7 } & Total & \% of Variance & Cumulative \% & Total & \% of Variance & Cumulative \% \\
\hline 1 & 4.815 & 48.153 & 48.153 & 4.815 & 48.153 & 48.153 \\
\hline 2 & 1.453 & 14.533 & 62.685 & 1.453 & 14.533 & 62.685 \\
\hline 3 & 1.003 & 10.030 & 72.716 & 1.003 & 10.030 & 72.716 \\
\hline 4 & 0.653 & 6.526 & 79.242 & & & \\
\hline
\end{tabular}

Table 2 The component score coefficient matrix

\begin{tabular}{|c|c|c|c|}
\hline \multirow{2}{*}{} & \multicolumn{3}{|c|}{ Component } \\
\cline { 2 - 4 } & 1 & 2 & 3 \\
\hline the concept of corporate social responsibility & 0.229 & -0.032 & -0.200 \\
\hline corporate social responsibility organizational system & -0.007 & 0.518 & -0.166 \\
\hline institutional system & 0.218 & 0.076 & -0.148 \\
\hline into the function of management & 0.229 & -0.091 & 0.008 \\
\hline into the business process & 0.224 & -0.092 & 0.049 \\
\hline overseas operation & -0.192 & 0.126 & 0.629 \\
\hline capacity building & 0.160 & 0.178 & -0.090 \\
\hline information disclosure & 0.015 & -0.230 & 0.609 \\
\hline stakeholder management & -0.128 & 0.541 & 0.014 \\
\hline performance management & 0.191 & -0.109 & 0.101 \\
\hline
\end{tabular}

According to table 4 , the three factors score functions are got:

Factor 1 score $=0.229 *$ the concept of corporate social responsibility- $0.007 *$ corporate social responsibility organizational system $+0.218^{*}$ institutional system $+0.229^{*}$ into the function of 
management $+0.224 *$ into the business process $-0.192 *$ overseas operation $+0.160 *$ capacity building $+0.015^{*}$ information disclosure- $0.128^{*}$ stakeholder management $+0.191 *$ performance management.

Factor 2 score $=-0.032 *$ the concept of corporate social responsibility $+0.518 *$ corporate social responsibility organizational system $+0.076^{*}$ institutional system- $0.091^{*}$ into the function of management- $0.092 *$ into the business process $+0.126 *$ overseas operation $+0.178^{*}$ capacity building$0.230 *$ information disclosure $+0.541 *$ stakeholder management $-0.109 *$ performance management.

Factor 3 score $=-0.200 *$ the concept of corporate social responsibility- $0.166 *$ corporate social responsibility organizational system- $0.148^{*}$ institutional system $+0.008^{*}$ into the function of management $+0.049 *$ into the business process $+0.629 *$ overseas operation- $0.090 *$ capacity building $+0.609 *$ information disclosure $+0.014^{*}$ stakeholder management $+0.101 *$ performance management.

Combined with table 1 can get the comprehensive scoring function of corporate social responsibility management level:

The comprehensive scoring function of corporate social responsibility management level in 2014 $=$ Factor 1 score*40.719/72.716+ Factor 2 score*17.523/72.716+ Factor 3 score*14.474/72.716.

According to this function, 65 central enterprises comprehensive score of corporate social responsibility management level in 2014 can be calculated.

\section{The Empirical Results and Analysis}

The model of the relationship between corporate social responsibility management comprehensive score (CSRMCS) and enterprise main business revenue growth (EMBRG) is built:

$\mathrm{CSRMCS}=\mathrm{a} * \mathrm{EMBRG}+\mathrm{b}+\beta$

In the formula, "a" is a variable coefficient, " $b$ " is a constant term and " $\beta$ " is the error term. This model reflects the relationship between corporate social responsibility management level and enterprise development ability.

Due to the number of data and the leap of data is relatively large within each 0.25 spacing, so 0.25 spacing is regarded as a unit in this paper, such as: 1-1.25,1.25-1.5,1.5-1.75,1.75-2,2-2.25,2.252.5,2.5-2.75,2.75-3,3-3.25,3.25-3.5,3.5-3.75,3.75-4,4-4.25. To take the average of all the data in each unit form the new data. Finally 13 set of new data is obtained and the paper carries out regression analysis for the 13 set of data. First of all, a scatter diagram is drawn based on the 13 set of data, such as figure 1. The figure shows that the main business revenue growth rate is smaller when corporate social responsibility management comprehensive score is greater. This indicates that the enterprise development ability are negatively related with corporate social responsibility management level at the same time.

Secondly, the data is carried out regression analysis. The result shows that an equal to -0.034 and b equal to 0.149 , so a yuan liner regression equation about corporate social responsibility management level and enterprise development ability is obtained. It is: CSRMCS=-0.034*EMBRG+0.149. 


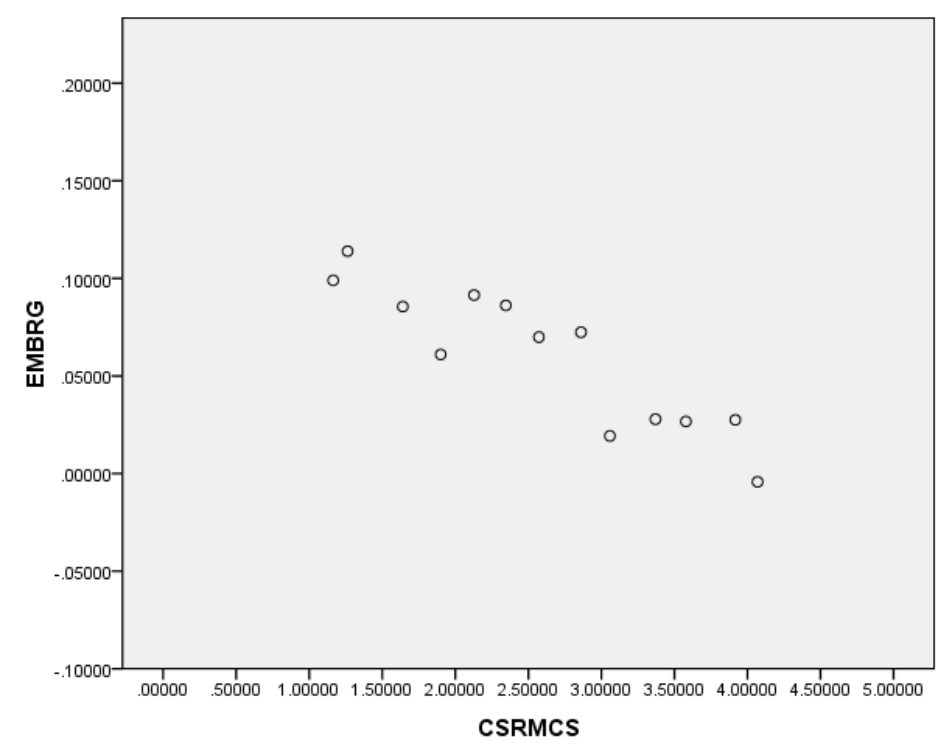

Fig. 1 The scatter diagram

\section{Summary}

This paper establishes a yuan regression model of the relationship between corporate social responsibility management comprehensive score and the main business revenue growth at the same period and carried out regression analysis by using the relevant data of 65 central enterprises in 2014 . The result found that corporate social responsibility management level is negatively related with enterprise development ability at the same time, namely in the same period, the enterprise development ability is lower when corporate social responsibility management level is higher.

\section{References}

[1] JIN Shuiying, WU Yingyu. The factor analysis and evaluation of enterprise development ability [J]. Statistics and Decision, 2008 (9): 73-75.

[2] WANG Qi, WU Chong, MA Gang. Corporate social responsibility accounting effect dynamic empirical analysis - based on life cycle theory[J]. Chinese Management Science, 2013, 21(11):542-548.

[3] JIN Shuiying, WU Yingyu. The relationship between the knowledge capital and enterprise development ability - empirical research based on panel data model[J]. Soft Science, 2008, 22(10): 94-99. 